\title{
Aislados y «des-aislados» (in)voluntarios a través de sus lenguas: dos casos aparentemente opuestos
}

\section{Livia Camargo}

iD https://orcid.org/0000-0003-0569-7786

livia.camargo.rj@gmail.com

\section{Bruna Franchetto}

iD https://orcid.org/0000-0001-7158-3838

Universidad Federal de Río de Janeiro (UFRJ), Brasil

bfranchetto@yahoo.com.br

RESUMEN

Este artículo agrupa dos relatos, en primera persona, de lingüistas que trabajan en proyectos de documentación de lenguas que están amenazadas. Se narran dos situaciones contrarias: la del guató -lengua que tiene solamente dos hablantes, sobrevivientes de un largo proceso de colonización - y la de la lengua del pueblo del Xinane, pueblo monolingüe de muy reciente contacto. Utilizamos esos dos ejemplos para problematizar el concepto de «aislamiento»: la situación del pueblo del Xinane que se trata, en realidad, de un des-aislamiento, cuidadosamente planeado y ejecutado por jóvenes, tras tres generaciones de aislamiento motivadas por el miedo a la violencia de los blancos. En contrapartida, la situación de Vicente -uno de los dos últimos hablantes de la lengua guató- se caracteriza, literalmente, mucho más como un aislamiento voluntario, a pesar de los más de cuatrocientos años de contacto de su fragmentado pueblo. Abordamos también los retos de crear metodologías de trabajo de campo para esos dos contextos diametralmente opuestos de vitalidad lingüistica.

Palabras clave: aislamiento, contacto, documentación lingüística, guató, pueblo del Xinane. 


\section{Isolated and (in)voluntary "de-isolated" through their languages: two seemingly opposite cases}

\section{$A B S T R A C T$}

This paper consists of two first-person reports of linguists working in the documentation of endangered languages. We narrate two opposite situations: that of Guató, a language with only two speakers, survivors of a long process of colonization, and that of the language spoken by the Xinane people, a monolingual recently-contacted group. We make use of these two examples to problematize the concept of «isolation»: the Xinane situation is, in fact, one of de-isolation (contact), carefully planned and executed by young people, after three generations of isolation motivated by white violence. Vicente, on the other hand, one of the two last speakers of the guato language can be more literally characterized as one of voluntary isolation, despite the 400 years of contact of his fragmented people. We also discuss the challenges of creating fieldwork methodologies in these two extremely contrastive contexts of language vitality.

Keywords: isolation, contact, documentation, linguistics, Guató, Xinane people 


\section{CONTEXTO}

Somos lingüistas y escribimos la primera versión de este texto en $2018^{1}$ no como un ejercicio académico, sino como la unión de dos relatos de memorias y experiencias en los cuales los testimonios en primera persona se abren para incluir otras voces. Se trata de casos que representan dos extremos y que nos invitan a problematizar la propia noción de aislamiento: por un lado, el «des-aislamiento» voluntario del pueblo xinane y por otro, el aislamiento (in)voluntario de los últimos hablantes de la lengua guató. Las dos situaciones son opuestas y complementarias, incluso para el lingüista que enfrenta el desafío de buscar y crear metodologías para la documentación de lenguas en ambientes contrastivamente monolingües: la del pueblo xinane, íntegra entre sus hablantes que se confrontan por curiosidad y necesidad con la lengua dominante, y el guató, sobreviviente en memorias sofocadas por la devastación colonizadora.

\section{YURA O DAWA:EN LAFRONTERA ENTRE INTÉRPRETE Y LINGÜISTA}

La voz testigo es la de la lingüista Livia Camargo, panóloga² dawa-nawá, que es el modo que los yura —indios pano de la región de Purus - usan para referirse a las personas no indígenas.

En el ámbito del «Projeto de Documentação de Línguas Indígenas (ProDoclin)» del «Museu do Indio» de Río de Janeiro ${ }^{3}$, me encontré con el recientemente

\footnotetext{
1 Presentación en el seminario internacional «Povos Indígenas em Isolamento Voluntário: Repensando as Abordagens Antropológicas». Río de Janeiro, 24-25 de septiembre de 2018, PPGAS/Museu Nacional-UFRJ, Kone Foundation y PUCP.

2 «Pano do Purus» o «Pano das Cabeceiras» es el subgrupo de la familia lingüística pano, que incluye los Huni Kuĩ (o Kaxinawá), los Amawaka y al complejo dialectal Yaminawa (Fleck, 2013).

3 ProDoclin: «Museu do Índio» - RJ/FUNAI y Unesco.
} 
«des-aislado» pueblo xinane ${ }^{4}$ : una familia extendida de 35 personas que viven en las márgenes del río Envira, en Acre. Se trata de dieciocho lenguas sobrevivientes de la familia pano, de cerca de 35 conocidas (Fleck, 2013), esparcidas por el sudeste amazónico, en Brasil, Perú y Bolivia. La lengua del pueblo xinane forma parte del complejo dialectal yaminawa, que incluye, entre otras lenguas, el jaminawa y el yawanawá. Esas dos lenguas son relevantes en este relato: el jaminawa por ser la lengua hablada por los intérpretes contratados por la Fundación Nacional del Indio - FUNAI para dar apoyo durante el contacto inicial con el pueblo xinane ${ }^{5}$, y el yawanawá por ser la lengua que estudié durante muchos años en el ámbito de dos proyectos de documentación ${ }^{6}$. Debido a este trabajo con el pueblo yawanawá, el equipo de la FUNAI me contactó: brindé un curso de capacitación en Documentación Lingüística para servidores del «Frente Envira» ${ }^{7}$ en la sede de la FUNAI, en Rio Branco en 2017; luego organicé un trabajo colaborativo para aplicar al proceso selectivo de ProDocLin, e inicié el proyecto de documentación de la lengua del pueblo xinane en 2018.

En mi primer viaje a campo llegué a $\mathrm{BAPE}^{8}$ Xinane con un temor enorme de ser vista como intérprete. Hacía poco tiempo que Frente Envira había despedido a los indios jaminawa que ejercían esa función desde el inicio del llamado «contacto». Su trabajo había sido fundamental para viabilizar procesos que podrían haber sido más complicados y conflictivos: desde la atención en salud hasta las interacciones cotidianas más simples. Después de un tiempo (o tal vez desde el mismo inicio), el discurso de los intérpretes se configuró como un tercer lugar de habla, fuera de control, con sus propias demandas, cuestionamientos y perspectivas, de tal modo que su participación en el equipo de la FUNAI se volvió insostenible ${ }^{9}$. La decisión de expulsar los intérpretes jaminawa no fue unánime: los indios del pueblo xinane ya habían construido lazos estrechos con los jaminawa; muchos de ellos incluso se trataban con términos de parentesco.

4 Meirelles (2018) se refiere a ese grupo por el etnónimo «txapanawa», que posteriormente fue rechazado por los propios indios. Por el hecho de que el grupo no tenía una autodeterminación, la FUNAI acordó llamarlos «Ppvo do Xinane», de acuerdo con el nombre del «igarapé» (curso de agua amazónico) donde habitaban en el momento del «contacto».

5 Ver Almeida (2021) sobre el trabajo de los intérpretes jaminawa a lo largo del proceso de contacto con el pueblo Xinane.

6 ProDoclin: Museu do Índio-RJ y Unesco (2010-2013); CNPq: «Línguas Indígenas Ameaçadas: pesquisa e teorias linguísticas para a revitalização» (2014-2017).

7 Frente de Proteção Etnoambiental Envira: equipo de la FUNAI responsable por el trabajo en BAPE Xinane.

8 «Base de Proteção Etnoambiental Xinane» de la FUNAI.

9 Ver Almeida (2021). 
Ellos eran los otros únicos yura en la base, hablaban como yura, comían como yura, interactuaban como yura (a pesar de vestirse y trabajar como dawa, esto los caracterizaba como «yura-dawa» según la perspectiva de los indios del pueblo xinane, según Almeida [2021]).

En medio de todo, no quería de ningún modo que los indios del pueblo xinane pensasen que yo estaba ahí para tomar el lugar de los intérpretes. Ellos obviamente percibieron de inmediato mi incompetencia e iban a quedar muy insatisfechos con la situación. Hasta entonces mi experiencia con lenguas pano se limitaba al contexto de documentación: trabajé siete años con la lengua yawanawá, que ya no se usa cotidianamente en la comunidad, con excepción de las personas más viejas. Aprendía la lengua en sesiones de «elicitación» ${ }^{10}$, de frase en frase, y no tenía ninguna presión para hablar. Ocasionalmente intentaba decir alguna cosa, sin embargo, volvía al portugués cuando me trababa en alguna palabra. Era posible pedir traducciones a los hablantes: preguntar lo que significaba cada frase, pedir evaluación de la gramaticalidad dentro de ciertos contextos... Yo no tendría nada de eso entre los indios del pueblo xinane. Tal vez pasaría dos meses allá sin entender nada y sin que ellos me transmitiesen alguna de sus ideas. Al menos, necesitaba certificarme de que ellos no asumirían que yo era una nueva intérprete.

Fue un alivio confirmar que, en este sentido, yo estaba siendo prejuiciosa. En todo caso, hace un tiempo que los intérpretes habían sido despedidos y los servidores y «mateiros» de la FUNAI ya se comunicaban bien con los indios del pueblo xinane, así como con los enfermeros de la SESAI ${ }^{11}$. Ellos estaban allí, en un contexto de interacción cotidiana, ya bastante familiarizados con las demandas de los indios, y con expectativas bien definidas sobre los temas de conversación, los pedidos y los chistes. Llegando con mi yawanawá de libro, era yo quien menos entendía lo que estaba sucediendo la mayor parte del tiempo.

A pesar de todo, algo interesante comenzó a suceder. Los indios de inmediato notaron que había algo en mi forma de hablar que era diferente de la de los dawa que conocían. Inicialmente no entendí qué era. Pensé que era porque conocía los términos de parentesco y lograba responder cuando ellos me preguntaban si tenía padre, madre, hermano mayor, hermano menor, tíos, abuelos etc. Esa es

10 El término «elicitación» se refiere a una sesión en la que la lingüista recolecta datos de la lengua, de forma sistemática y junto con los hablantes nativos: pueden registrarse paradigmas gramaticales, salir de dudas sobre la pronunciación o el significado de las palabras y frases, solicitar una evaluación de la gramaticalidad de determinadas construcciones, o solicitar traducciones en los casos en que los consultores sean bilingües.

11 Secretaría Especial de Saúde Indígena, órgano del Ministério da Saúde de Brasil. 
una primera conversación típica entre los indios de Xinane: ellos quieren saber si uno tiene familia. Si hay fotos para mostrar, mucho mejor. Esa conversación recuerda la hipótesis de Rolando (2018) según la cual los jóvenes indios de Xinane, al momento del contacto, necesitaban certificarse de que sus interlocutores los agentes de la FUNAI y los indios ashaninka de la aldea Simpatia — tenían «cuerpos» $\left(\right.$ yura $\left.^{12}\right)$ lo suficientemente semejantes a los suyos, para que así pudiesen desarrollar una relación viable con ellos. Primero es necesario certificarse de que ese otro que llega también es gente. Confirmé entonces mi hipótesis según la cual la lengua yawanawá y la del pueblo xinane son bastante cercanas. Pero no era solo eso. De a poco comencé a percibir que los indios venían hasta mí para traer demandas y cuestionamientos, pidiendo que los comunicase a los funcionarios de la base. Para mí esto no tenía ningún sentido: había llegado recientemente y no entendía las políticas de la BAPE. En realidad, entendía muy poco de qué me hablaban, pero por algún motivo ellos no percibían esto.

Un día, mientras pasaba tiempo con Hwediaxta, recibí una respuesta explícita para aquella incógnita. Pasé muchas horas con ella, la hermana Toshko y los niños, andando por los alrededores de la BAPE, por la floresta, por las casas de los familiares, o simplemente tejiendo abalorios, cocinando, comiendo, cosiendo o jugando con los monos que tenían como mascotas. Uno de los elementos principales de la metodología de trabajo de campo con un pueblo monolingüe es, sin duda, el tiempo. Muchas veces ese tiempo pasa sin ninguna entrevista formal, ninguna pregunta proferida por la lingüista, nada que un observador externo caracterizaría como «trabajo». Es tiempo de observación, de escucha, de inmersión y de choque cultural. Ese día, específicamente, estaba sentada en la hamaca de la casa de Hwediaxta grabando una sesión de elicitación bastante informal: a mi alrededor los niños hacían alboroto. Ese tipo de sesión siempre comenzaba cuando yo le pedía a ella que corrigiera mi habla medio equivocada. Entonces yo decía una frase y ella la repetía de forma correcta — ¿Iskaramẽ yura tsãi? — ¿Es así como los yura hablan? Le pregunto —Ẽ tapiaba, ea yuiwe — No sé, me cuenta.

12 En las lenguas del complejo dialectal yaminawa, la palabra yura quiere decir tanto «persona, gente» como «pariente, familiar», y también «cuerpo». Mientras que para nosotros esta palabra puede parecer polisémica, esos múltiples significados reflejan una noción central de la cosmología de esos pueblos entre los que el grupo comparte una identidad corporal. Según Perez-Gil (2003, p. 27): «El concepto de yura condensa el principio de compartir sustancias corporales entre parientes cercanos, y articula la individualidad con la identidad grupal. Utilizar la idea de cuerpo para referirse a la colectividad no es una metáfora: expresa el hecho de que el cuerpo individual no acaba en la frontera impuesta por la piel, sino que forma parte de un cuerpo supra-individual». 
La idea de ese día era recolectar unas frases simples, en ese caso una construcción de unión de tipo $X$ es $Y$. Dije entonces la siguiente frase: "Yo soy dawa, usted es yura». Para sorpresa mía, ella levantó la cabeza, quitando por primera vez los ojos de los abalorios, después de un buen tiempo de quedarse concentrada, me dijo: Mĩ dawaba! —Usted no es dawa! —Mĩ yura! —Usted es yura: usted entiende lo que digo, habla como yo. Cuando hablamos con los dawa ellos solo hablan awamẽ, awamẽ — ¿Qué? ¿Qué? —no se puede conversar con ellos. Usted se queda aquí con nosotros, conversa con nosotros. Mĩ yura, mĩ dawaba!

Después de un momento de absoluta consternación, entendí finalmente la solución de la incógnita que me acompañaba desde mi llegada a la BAPE. Es claro que mi socialización tuvo peso, mi deseo por pasar tiempo con Hwediaxta y su familia, de compartir conocimientos, de querer aprender las cosas de ellos, así como estar dispuesta a explicar las extrañezas del mundo de los dawa. Tal vez la inconformidad de mi nueva amiga de caracterizarme como dawa se daba porque ella veía en nuestra relación lo que Rolando (2018) llama de «mutua incorporación no-jerárquica»: un proceso de transformación mutua y eliminación de diferencias que posibilitaba nuestra armoniosa convivencia. En todo caso, después de diez años de convivencia con los yawanawá, yo sabía la importancia de comer juntos, y del papel central de la generosidad en el código de ética de los pueblos pano de la región (Siskind, 1973): comía con ellos comida de yura y le llevaba a ellos lo que tenía permiso de compartir ${ }^{13}$. A pesar de eso, también sabía que era inevitablemente categorizada como mezquina por no poder ofrecer los dulces, sal o alimentos industrializados que ellos sabían que nosotros consumíamos. No podía ser solo eso.

Fue en esa interacción con Hwediaxta que finalmente quedó claro para mí que aquello que faltaba en mi habla y en la de los demás dawa era sintaxis. Por más que mi conocimiento de la lengua fuese bastante limitado, mis frases tenían flexión de tiempo y aspecto, marcación de caso ergativo, concordancia de plural, posposiciones. Eran frases de hecho, no solo palabras sueltas que tenían sentido en contexto. Halagada por ser categorizada como «gente» por mi amiga más joven, entendí finalmente el motivo de estar siendo designada como intérprete por los indios. De ahí en adelante, mi recelo inicial se deshizo por completo y acepté tomar con calma mi atribución (todavía sin querer mostrar lo poco que entendía

13 Con el objetivo de mantener la salud de la comunidad, las reglas de la BAPE Xinane no permiten que los alimentos industrializados o que contienen sal y azúcar puedan ser ofrecidos a los indios. 
de su lengua). Hice el papel de intérprete en diversas situaciones importantes, la mayoría de ellas siendo tentativas nuestras - hablando ahora de la perspectiva de dawa, que es mi único lugar de habla — o de ellos, yura, de transponer alguna situación de desentendimiento o choque cultural.

Por iniciativa de una médica que estaba de paso por la base, por ejemplo, intermedié un círculo de mujeres para conversar sobre higiene y salud. Hwediaxta participó activamente de ese encuentro, elaborando siempre las frases que yo traducía, dando profundidad y elocuencia a mi limitado vocabulario. Fui intérprete cuando una enfermera necesitó preguntar a una familia qué hacer con un feto abortado. Espero el momento de hablar mientras veo al padre enseñar anatomía a los hijos, aglomerados en silencio alrededor de aquel pequeño ser no-nacido, que podría haberse convertido en el más joven de la familia. Traje para los dawa demandas sobre gasolina, dolores menstruales, jabón, infecciones causadas por la mosca Dermatobia hominis...Y llevé a los yura todo tipo de preguntas, desde cuál planta medicinal se usa para determinada cosa hasta si ellos querían ir y participar de un encuentro de pueblos de contacto reciente en Brasilia. Para esta última consulta pasé días preparando mi discurso; escribiendo y reescribiendo lo que necesitaba decir, preocupándome por explicar exactamente de qué se trataba. Quedó claro que aceptaron la invitación: según los propios jóvenes $y u r a$, conocer el mundo que los rodea fue uno de los grandes motivadores del «des-aislamiento» encabezado por ellos ${ }^{14}$. Y era claro que por más articulada que yo intentase sonar en aquel momento, ellos no entenderían lo que puede ser un encuentro de pueblo de contacto reciente. Era apenas hace cuatro años que los xinane yura se habían mudado de forma definitiva a las cercanías de la BAPE, en las márgenes del río Envira ${ }^{15}$.

En medio de todo eso, yo necesitaba defender mi papel de lingüista. Fue interesante constatar la incompatibilidad de ejercer dos papeles y el contraste que existe entre las dos funciones, desde el punto de vista lingüístico. Por parte de los indios xinane, y como «intérprete», me encontraba con una aceptación restricta de absolutamente todo lo que decía. Hace cuatro años ellos conviven con hablantes de muchas lenguas diferentes: los servidores de la FUNAI y la SESAI; los ashaninka, que son los vecinos más próximos y trabajaban en la BAPE; los kulina, que ellos encuentran cuando bajan el río; los jaminawa, que trabajaron

\footnotetext{
14 Ver Torres (2018), Rolando (2018), Gow (2018) y Almeida (2021) para diferentes perspectivas sobre las nociones de aislamiento y contacto.

15 Ver Meirelles (2018), Rolando (2018) y Almeida (2021) sobre el «primer contacto» del pueblo xinane.
} 
como intérpretes, o los shanenawa, que los recibieron en la ciudad de Feijó. El habla del pueblo xinane está repleta de palabras de otras lenguas; ya se volvió un hábito incluirlas en el discurso, aun cuando están hablando entre sí. En fin, la cuestión relevante es que los indios del pueblo xinane están dispuestos a aceptar lo que decimos de forma irrestricta desde que la comunicación se dé.

Por otro lado, el hecho de ser lingüista depende de juicios de gramaticalidad: si alguien me corrige cuando hablo con errores, esa persona necesita saber si esa palabra es de ellos o de los jaminawa, o incluso si es un término prestado del portugués que se volvió irreconocible. Sin embargo, no es así como ellos operan - o por lo menos eso fue lo que pensé inicialmente-, entonces la forma que encontré de demarcar mi lugar fue definiendo explícitamente el comienzo y el fin de cada sesión de elicitación.

Ese abordaje se volvió una parte importante de la metodología de campo que experimenté y adopté para trabajar con el pueblo xinane. Junto a la recolección de situaciones naturales del uso de la lengua - conversaciones espontáneas, sesiones de contar historias personales y narrativas míticas, peleas, cantos, rituales, etc.las sesiones de elicitación me permitieron no solo aclarar cuestiones relativas al material recolectado anteriormente y solicitar paradigmas gramaticales, sino que también tenían el papel importante de delimitar el momento de hablar «como hablan los yura». La metodología que adopté refleja la propuesta de Chelliah (2001) de entrelazar la recolección de textos con la elicitación de forma modular y armoniosa, comprendiendo la complementariedad de las dos prácticas para la producción de datos lingüísticos confiables. Mi foco recae sobre las sesiones de elicitación, que fueron la principal herramienta que usé para dar cuenta del desafío de aceptación irrestricta por los xinane yura de mi habla. Así, mis momentos de «ser lingüista» se desenvolvían de la siguiente forma: yo llamaba a dos personas a un lugar silencioso, prendía la grabadora — que bauticé txada, japinim, que es un pájaro de la región que imita el canto de los otros pájaros- y siempre daba algún tipo de instrucción. Cuando elicitaba frases, usaba la técnica que describí para entrevistar a Hwediaxta: digo que voy a hablar un poco mal y pido que la persona hable la misma cosa y me corrija. Siempre erraba algunas frases a propósito, como una forma de control, para ver si ellos realmente me corregían. Generalmente funcionaba. Hubo sesiones en las que elicité apenas ítems lexicales: señalaba para objetos, o mostraba imágenes en el computador y decía: «en mi lengua, el nombre de eso es esto, en la lengua de los yawanawá el nombre es tal. ¿Cómo es el nombre en su lengua?». Otro tipo de sesión de elicitación que utilicé con frecuencia incluía una forma de «teatro»: hacía mímicas o creaba una escena 
con ayuda de los amigos dawa y preguntaba: «¿Qué estoy haciendo». Ese tipo de sesión siempre funcionaba mejor con algunas personas que con otras. Había quien simplemente se quedaba mirándome un poco confundido y me devolvía la pregunta: «¿Qué es lo que usted está haciendo?». Rápidamente encontré a las personas adecuadas para este tipo de sesión: la propia Hwediaxta era una que soltaba carcajadas y se divertía, como si fuera un juego de adivinanzas.

Esa metodología experimental rindió buenos frutos. Aun así, dejó algunas lagunas, generalmente en los momentos en que el ser «intérprete» y el ser «lingüista» se confunden. Tanto yo como los yura de verdad, queríamos lograr comunicarnos y ese sentimiento a veces invadía las propias sesiones de elicitación, por más separación que yo intentase imponer. Un poco más controlada era la elicitación de palabras sueltas: la palabra de los dawa es esa, la de ustedes es aquella. Pero para la elicitación de frases, yo usaba el yawanawá como base.

La palabra rete, por ejemplo, quiere decir «matar» en diversas lenguas del complejo dialectal jaminawa y es una palabra muy común en un grupo que vive de la caza. Comencé a usarla, y como todos entendían, yo simplemente presupuse que era una palabra de su lengua. En sesiones de elicitación de frases siempre había algo para ser corregido: mi prosodia, mi marcación de caso, mi pronunciación de ciertos fonemas... entonces esa palabra «matar» fue una que pasó desapercibida. Ellos entendían, entonces no me corregían, y yo seguí hasta el final del viaje de campo pensando que era una palabra de ellos. Fue solo cuando volví a la ciudad que descubrí que la palabra de los xinane yura para matar es rixki, no rete. $\mathrm{Y}$ el contexto del descubrimiento fue una lección en sí. Habíamos agendado un taller poscampo, en la sede de la FUNAI en Rio Branco, con el objetivo de capacitar a los servidores de Frente Envira en metodologías de documentación y presentar un poco lo que había sido realizado durante mi viaje de campo. Por coincidencia, dos indios del pueblo xinane habían ido para Rio Branco en la misma época, y acabaron participando en el taller. Los dos observaban todo lo que yo presentaba: en el primer día se interesaron por los videos y audios del diccionario, pero fue a partir del segundo día que comenzaron a participar como verdaderos especialistas. El asunto era morfología. Proyecté una serie de frases en la lengua de los xinane yura con sus debidas traducciones y nosotros íbamos separando los morfemas uno por uno, buscando entender los significados. Ese ejercicio tomó por completo la atención de Kãma, el más viejo de los dos indios presentes. Él iba escuchando lo que decíamos, corrigiendo las pronunciaciones; yo le preguntaba si estaba correcta y él decía que sí. Hasta que llegamos a una frase con la palabra rete. En ese momento, él se levantó y comenzó a explicar 
que aquella palabra era de dawa y no de ellos. Dijo que los jaminawa hablaban rete, pero que la palabra de ellos de verdad era rixki. Sorpresa, incorporé la nueva palabra inmediatamente y expliqué la situación a los presentes.

Aunque corta, esa corrección ayudó a redefinir nuestros papeles en aquel taller. Quedó claro, a partir de ese momento, que nosotros, dawa, éramos los aprendices, y que los yura allí presentes eran los maestros especialistas. Los dos comenzaron a contribuir significativamente con una serie de comentarios y explicaciones en los que demostraban tener una fina consciencia metalingüística de fenómenos complejos, como distinciones tonales. Kãma, por ejemplo, ilustró con las manos el par mínimo [şínà] [șìnà], señalando arriba y abajo para indicar tonos altos y bajos. Xina que era el más joven, corregía nuestras pronunciaciones y comentaba que la lengua de los dawa es más «suave»: por el contrario, era necesario hablar con la lengua firme para lograr pronunciar sus palabras correctamente. Y eso fue apenas el comienzo. En el último día, cerramos el taller con una visita a la secretaría de educación de Acre, donde fuimos recibidos por un grupo de profesores e investigadores. El grupo incluía dos yura, hablantes de shanenawa y hãtxa kuĩ, que son lenguas de la misma familia pano. Por sugerencia del secretario de educación, nos sentamos en un gran círculo y nos presentamos uno por uno. Cuando llegó la vez de Kãma, yo le dije en la lengua de los yura: «Kãma, ¿quién es usted? Los dawa quieren saber, diles». No creí que fuera a decir algo más allá de su nombre, siguiendo más o menos el formato que las presentaciones de cada uno habían seguido hasta entonces. Pero para sorpresa de todos, lo que siguió fue un monólogo de aproximadamente cuarenta minutos, que hizo explícita una vez más la divergencia de las nociones respecto al encuentro de uno con otro, como discutidas por Rolando (2018). Afirmando su condición de «gente», Kãma dio un panorama de quiénes son los xinane yura: habló de las relaciones de parentesco, del lugar en el que viven, de lo que cultivan, de las herramientas que usan citando en portugués los nombres de todo lo que él sabía-, de los animales que comen y los que no, de los nombres de las partes del cuerpo y de las respectivas plantas medicinales que conocen, de las aldeas vecinas y de las palabras de otras lenguas de la región que él conocía. Fue una larga y elaborada respuesta para la pregunta «¿quién es usted?», que acabó colocándome de nuevo en la posición de intérprete frente a aquel grupo: yo iba intentando traducir simultáneamente lo que Kãma decía, esta vez con la ayuda de dos profesores indígenas presentes.

Fue de esta forma como mi experiencia de campo con los indios de Xinane transcurrió: siempre en la frontera entre intérprete y lingüista, aceptando cada vez más esa dualidad contradictoria. Ciertamente el mayor desafío de ser lingüista en 
ese contexto era desarrollar metodologías que neutralizaran ese lugar de casi-yura (aun cuando momentáneamente) y colocaran a los yura de verdad en el papel de los especialistas. Poco a poco, los indios de Xinane continúan su proceso de «des-aislamiento» voluntario.

\section{GUATÓ: LENGUA AISLADA, DE AISLADOS CON CUATROCIENTOS AÑOS DE «CONTACTO»}

Las innumerables áreas de la región del Pantanal, al suroeste de Brasil, ya fueron habitadas por diferentes pueblos de distintas lenguas, que mantenían entre sí relaciones de alianza, intercambio y conflicto que se extendían de la costa atlántica hasta el piedemonte andino. La diversidad indígena del Pantanal se constituyó entre los años 3000 y 2000 AP, pero la ocupación humana del lugar se remonta a por lo menos 8000 años atrás, habiéndose consolidado con el aumento del número de montículos de tierra ${ }^{16}$ entre 5000 y 3000 AP (Eremites y Milheira, 2020). De esa larga historia indígena del Pantanal, quedan hoy apenas los Guató, que en el siglo XVI se afrontaron con la invasión europea, inicialmente española y más tarde lusa. Como ellos, otros pueblos, hoy extinguidos, habitaron y modificaron el paisaje del Pantanal ${ }^{17}$.

Las haciendas expropiaron las tierras de los Guató y se apropiaron de su trabajo. Como afirman Balykova y Godoy (2020, p. 4): «el pueblo Guató no formaba asentamientos nucleados, sino micro comunidades de habla de familias

16 Eremites y Milheira (2020) realizaron investigaciones recientes sobre los montículos guató, específicamente en la TI Bahia dos Guatós en MT. Los montículos —morobohó en guató- son sitios arqueológicos compuestos por elevaciones de tierra (mounds) y transformaciones topográficas circunstantes. Los montículos fueron construidos por diferentes poblaciones indígenas, como puntos artificialmente elevados en las regiones Amazónica, Platina y otras. Como afirman Eremites y Milheira (2020): «Se trata de lugares en los que elementos de depresiones topográficas, elevaciones en tierra, zanjas, canales y sedimentos manejados están asociados a vestigios materiales como vasijas cerámicas, instrumentos líticos, restos alimentares y cuerpos humanos [...] Componen marcas espaciales y estructuras materiales que denotan significados culturales y agencias sociales [...] Los Guató en general, se identifican con los montículos indígenas, los vestigios arqueológicos del Pantanal más antiguos conocidos en el tiempo presente, y encapsulan conocimientos tradicionales, cosmologías e historias humanas y ambientales». Schmidt (1951) ya había percibido la relación entre la construcción de los aterros y el enriquecimiento antrópico del suelo en sus visitas entre los guató en 1901, 1910 y 1928.

17 Confrontar la presentación de Gustavo Godoy en el Workshop Towards a typology of regional multilingual systems: West Africa and Amazonia (setembro 2017) en http://nupeli-gela.weebly. com/guatoacute.html 
dispersas y dispersables». No obstante, los montículos continuaron representando referencias no solo territoriales, sino también históricas y cosmológicas. La lengua, sin embargo, languideció por la desagregación social dada por la desintegración de las familias. Esto se dio por varias razones; entre las principales se encuentran epidemias y la presión colonizadora. Las cadenas de transmisión entre las generaciones se rompieron. Fue entre 1940 y 1950 que la brecha se aceleró y esto dispersó a los guató por las aguas y las ciudades. En esta época, el «Serviço de Proteção aos Índios», órgano gubernamental brasileño, declaraba su supuesta extinción. No obstante, los guató, fragmentados, remanentes aislados de memorias evanescentes de una lengua aislada y tonal, continuaron existiendo. Y volvieron a emerger del silencio cuando una parte de ellos se organizó en la década de 1970, para exigir sus derechos territoriales, culminando con la demarcación de la Terra Indígena Guató (en Mato Grosso do Sul), homologada en 2003.

En los años 2000 fueron retomados los estudios de identificación para una tierra indígena guató en Mato Grosso. En esta época, los Guató definían su lugar como aldea São Benedito (nombre de una hacienda), en el municipio de Barão de Melgaço. En 2012, los trabajos de demarcación de la Terra Indígena Baía dos Guató (MT) solo fueron concluidos con la protección de la Policía Federal. La homologación se dio en 2018, pero luego pasó a ser objeto de demandas por supuestos propietarios de las tierras de la región. Más de una centena de guató ocupa y reivindica este pedazo de tierra en la orilla del río Cuiabá. Los dos grupos guató: el del sur-mato-grossense y el del norte-mato-grossense, saben de la existencia de los otros, pero hasta hoy no mantienen contacto entre sí.

La voz que ahora escribe es múltiple, es la de los miembros de un equipo de investigación: Bruna Franchetto, Gustavo Godoy, Kristina Balykova y Walter Alves.

Nuestro camino comenzó en la Terra Indígena Baía dos Guató, y en respuesta a un llamado dramático que llegó de los guató de Mato Grosso en 2013: ayudar en la creación de una escuela que debería marcar la reocupación territorial con la reunión de familias dispersas, y que atendiese a la demanda del rescate de la lengua olvidada. Ni el más viejo del grupo, con más de cien años, lograba hacer aflorar de su debilitada memoria algunos fragmentos de palabras y frases. En la recuperación territorial los líderes guató escuchaban, por un lado, que ellos eran «menos indios» por no hablar más la lengua de sus ancestros, y por el otro, que «el idioma indígena no vale». 
En agosto de 2016, llegamos a TI Baía dos Guató para la realización del primer taller de un posible rescate de la lengua ${ }^{18}$. La situación y el contexto exigían la adopción y adaptación de la metodología conocida como «documentación de emergencia», atestiguada en un viaje anterior, en 2014, que llevó a las autoras y al lingüista Rafael Nonato a conocer experiencias de revitalización lingüística en Australia ${ }^{19}$.

Australia tiene, probablemente, el peor registro de pérdidas de lenguas indígenas, que de 250 a 300 , con 600-800 dialectos, fueron reducidas a apenas trece, todavía razonablemente «saludables», es decir, aun adquiridas por los niños a través de transmisión intergeneracional. Amery (2017) describe y analiza una de las experiencias más exitosas de revitalización de una lengua nativa en Australia. El kaurna, lengua de las Planicies de Adelaide, desapareció en la primera fase de colonización británica, pero de ella quedaron registros escritos producidos en la primera mitad del siglo XIX, entre los cuales se encontraba una buena gramática. A lo largo de los últimos veinticinco años, y aún en la actualidad, esta documentación, exclusivamente escrita fue la base de un movimiento sostenible de recuperación de los esfuerzos por los cuales los pueblos aborígenes están intentando recuperar o revitalizar sus lenguas remanentes. La experiencia kaurna nos inspiró a iniciar el trabajo con los guató, anhelando una futura $-\mathrm{y}$ tal vez posible- revitalización.

18 Viajes e investigaciones, entre 2016 y 2018 concretaron uno de los componentes del proyecto «Línguas Indígenas ameaçadas: pesquisa e teorias linguísticas para a revitalização» (CNPq, 2015-2018, recuperado de http://nupeli-gela.weebly.com/revitalizaccedilatildeo.html). El subproyecto guató fue ejecutado por Bruna Franchetto (coautora del presente artículo) en 2016, y por Gustavo Godoy, Kristina Balykova y Walter Alves hasta 2018. Godoy y Balykova continúan el trabajo de documentación lingüística y de producción de un diccionario en el ámbito del «Projeto de Documentação de Línguas Indígenas» (ProDoclin, Museu do ÍndioFUNAI, Unesco).

19 El viaje a Australia, donde permanecimos por tres meses, en 2014, fue posible gracias a un convenio entre la FUNAI-Museu do Índio-RJ, institución gubernamental brasileña, y el Instituto Australiano de Estudos Aborígenes e das Ilhas do Estreito de Torres - AIATSIS, institución gubernamental australiana. El acuerdo tenía por objeto la cooperación para el intercambio de conocimientos y experiencias respecto de la documentación y protección de lenguas indígenas. Un informe detallado de la estadía australiana y de las experiencias junto a diversos centros dedicados a la revitalización de lenguas nativas se encuentra en http://prodoclin.blogspot. com/2014/02/normal-0-21-false-false-false-pt-br-x.html. Ver Franchetto et al. (2014) para una primera comparación entre los contextos brasileño y australiano, con la delineación del proyecto mencionado CNPq (nota 18), que concretaría la documentación de la lengua guató, entre otras, en Brasil. 
En Brasil no es menos impresionante la pérdida lingüística. A lo largo de cinco siglos de colonización, desapareció más del $80 \%$ de lenguas existentes en el momento de la conquista; sin embargo hoy en día aún sobreviven entre 150 y 160 con diferentes grados de vitalidad. Todo indicaba que estábamos, con el guató, frente a otra lengua «extinta», aunque en tiempos más recientes y con alguna documentación escrita y algunos registros grabados. Teníamos acceso a las preciosas observaciones de Schmidt de inicios del siglo XX, y las descripciones de aspectos de la gramática hechas por Palácio (1984) y de la fonología por Postigo (2009), además de pequeñas listas de palabras (Castelnau, 1949 [1851]; Rondon, 1938, Wilson, 1959). El etnólogo alemán Max Schmidt documentó fenómenos de la lengua y dejó listas de palabras y frases (Schmidt, 1942a y 1942b). Schmidt notó la reticencia de los guató para comunicarle «algunos apartes en su lengua con traducción portuguesa» (Schmidt, 1942a, p. 283) ${ }^{20}$.

El equipo, compuesto por Franchetto, Godoy, y en seguida por Balykova y Alves, preparó el trabajo de campo entre los guató de Mato Grosso, organizando y estudiando material documental y lingüístico existente, incluyendo grabaciones recuperadas de los acervos de las lingüistas Adair Palácio y Adriana Postigo, quienes realizaron investigaciones con aquellos que parecían ser los últimos hablantes en los años ochenta, y del acervo de Joel Pizzini, director del filme 500 Almas (2007) ${ }^{21}$. Comenzó a ser construido un acervo digital que paulatinamente fue ampliado, actualizado y compartido con los guató. Además de eso, entrevistamos familias e individuos de los remanentes guató de MT, tratando temas como la pérdida de la lengua, la situación de la tierra, las trayectorias de vida, y las técnicas y conocimientos de subsistencia.

La primera etapa del trabajo de documentación de emergencia y la demanda inmediata y urgente de los guató de Mato Grosso presentaron un resultado que nos pareció impactante: una primera cartilla de iniciación a la lengua guató para aquellos que no la hablan: Goxéuvý iótý («lengua guató»). La cartilla contiene un pequeño vocabulario con palabras y frases básicas, presentadas a través de dibujos hechos por los participantes del taller que escenifican pequeños diálogos

20 Schmidt (2018) ofrece una nueva traducción del alemán para el portugués del capítulo VIII, sobre la lengua guató de Indianerstudien in Zentralbrasilien (1905). La traducción es de Kristina Balykova, con prefacio de Gustavo Godoy y de la propia traductora. La transcripción de los datos recolectados por Schmidt fue recolectada con base en los estudios de Palácio (1984) y Postigo (2009), y en los resultados de la nueva documentación realizada con los últimos dos hablantes del guató, entre octubre de 2016 y agosto de 2017.

21 Agradecemos a Adriana Postigo y a Joel Pizzini por habernos permitido el acceso a las grabaciones de sus acervos, aquellas realizadas por Palácio. 
o representan animales, plantas y objetos, o a través de fotos. Una versión grabada en audio circuló rápidamente por los celulares de los participantes, sobre todo entre los más jóvenes, que pasaron a memorizar todo y a entrenar hablando. El nuevo guató escrito puede ser considerado una nueva variedad, simplificada si se compara con el guató tradicional: buscamos mantener algo de su melodía tonal escribiendo el tono alto con acento agudo ${ }^{22}$.

Satisfechos con la recepción de la primera cartilla, continuamos insatisfechos por no haber logrado encontrar ningún hablante de la lengua guató. El segundo viaje, en octubre de 2016 cambió drásticamente nuestras expectativas. Gustavo Godoy llegó a la parte baja del río São Lourenço, donde vive Vicente da Silva [ $\left.\widehat{d}{ }_{3} g^{w}{ }^{w} p o\right]$, que nos pareció el último refugio de la lengua guató. Enseguida, en la ciudad de Corumbá, Gustavo descubrió a Eufrásia, quien desde hace algunas décadas no hablaba en guató (Franchetto y Godoy, 2017). En campo se hizo posible una documentación lingüística efectiva movilizando las metodologías actuales para la recolección de datos.

Vicente $\widehat{d}{ }_{3} g^{w}{ }^{w}$ ́p s es un guato en aislamiento voluntario, un eremita que vive en la boca de la parte baja del río São Lourenço, en pleno Pantanal. Él es uno de los dos últimos hablantes de la lengua guató, aislada (resquicios de una lengua que sobrevivió al desaparecimiento de lenguas hermanas). Vicente es arisco y solitario, pero estuvo de acuerdo en recibir a Gustavo en octubre de 2016, en su casa, donde vive con casi veinte gatos, tres perros y algunos muitús semidomésticos.

Diariamente llena las corazas de cocodrilo que tiene en su patio, para alimentar sus mascotas salvajes. Tiene un cultivo de yuca; plantaba maíz, pero ahora el suelo está muy seco; tenía sandías, pero ahora faltan semillas. Vicente se transporta usando una vieja canoa, remendada con latas y arcilla, que mueve con su remo de punta fina. Por la mañana sale a pescar, acostumbra a cazar chigüiros, aunque hoy en día en el Pantanal disminuyó el número de estos grandes roedores. En la región siempre hay jaguares y cocodrilos. En uno de los gallos del árbol de mango, cerca del puerto de su casa se encontraban remos, arpones, y varas de pescar, un viejo bodoque con el arco quebrado. Mantuvo gran parte de los utensilios que componían la cultura material guató de otros tiempos (Franchetto y Godoy, 2017, p. 292).

Vicente mostró su tensa sonrisa los primeros días, dispuesto a enseñar algo del guató que antes estaba en la punta de su lengua. En el transcurso de las elicitaciones, buscaba palabras y construcciones. Vicente soltaba un click de decepción,

22 Una segunda cartilla fue producida, con nuevas palabras, frases y diálogos, después de dos talleres realizados en 2017, en TI Baía dos Guatós (MT) y en la ciudad de Corumbá (MS), en 2017. 
bajaba la mirada, buscaba palabras perdidas y soltaba un «imierda!» en tono de fracaso. Comenzaba a hablar en portugués, dejaba la sentencia e intentaba nuevamente en guató. Ya era la segunda vez que Vicente olvidaba la lengua. Cuando fue a trabajar río abajo, lejos de la familia, en un barco frutero y en haciendas, su habla guató se fue debilitando. Luego de volver a vivir con su madre, la señora Júlia, su desempeño lingüístico volvió. Ahora, Vicente no volverá a conversar.

Gustavo se quedó preparando listas con nuevas palabras, paradigmas y términos de parentesco. Intentaría registrar una narrativa. Al tercer día del primer encuentro, Vicente se alejó con su canoa y volvió con cara de pesar.

«Extendió la palma de la mano en un gesto de impedimento: — «Para ahí! ¡Para ahí! Pare de irritarme». «¿Puedo volver mañana u otro día?», preguntó Gustavo — «No, se acabó» (ídem, p. 293).

Otra hablante de la lengua guató sería «descubierta» en 2017: Gustavo Godoy y Walter Alves fueron a Corumbá a visitar a Eufrásia Ferreira, en la periferia de la ciudad, a poca distancia de la frontera con Bolivia. Si la sonrisa de Vicente era tensa, revelando el sufrimiento, la vergüenza y la rabia que acompañaban cada inmersión en los recuerdos de su lengua antigua, por otro lado, risas sueltas, ruidosas y casi compulsivas marcaban cada memoria que afloraban en la boca de Eufrásia, cuyo nombre en guató es [ $\widehat{d}$ ariguka], no solamente en su pequeña y más humilde casa, sino también en la lancha que la llevaría, en junio de 2018, a rencontrar sus primos en la Ilha de Ínsua y al encuentro con Vicente. No se acordaban el uno del otro, intentaron conversar. En el encuentro de dos aislados, por un lado, había una tensa sonrisa y por el otro, tensas carcajadas. Esta vez Vicente estaba bien humorado y recibió bien a los visitantes ${ }^{23}$, y según el relato de Gustavo Godoy, cuando vio que él ya lograba hablar algunas cosas en guató, quiso enseñar más palabras y hasta pidió que prendieran la grabadora. Si Eufrásia recordaba pocos nombres de aves, Vicente nombró una buena parte de los que le fueron mostrados en un libro de aves del Pantanal. Además, recordaba varios neologismos del siglo XX («avión», «teléfono», «pila», etc.). Por otro lado, Eufrásia era más comunicativa y rápida en formar frases en guató, ensayando una posible conversación con Vicente preguntando, por ejemplo, si él freía gatos y los comía con espaguetis ${ }^{24}$.

23 Además de Eufrásia: Gustavo Godoy, Kristina Balykova, Luiz Carlos, cacique de Uberaba, Fernando, habitante de Uberaba (TI Guató), y el piloto de la lancha.

24 El vídeo «Lembranças em Guató» (33:46 mn), producido en 2018, registra los encuentros con y entre Vicente y Eufrásia. Está disponible en http://nupeli-gela.weebly.com/guatoacute.html 
Después de cuatro siglos de despojo y explotación, declarados extinguidos un pueblo y su lengua, los descendientes guató, aislados y dispersos en las haciendas y periferias de las ciudades, resurgieron de sus escondrijos a cielo abierto. Hoy, el equipo de lingüistas y antropólogos continúa trabajando con la prisa de los últimos días, con los «des-aislados» Vicente y Eufrásia, en una documentación de emergencia que busca y crea metodologías para extraer y registrar memorias raídas, pasando por sufrimientos y vergüenzas. Memorias que cada vez más parecen aflorar para gritar: la lengua guató existe.

\section{CONSIDERACIONES FINALES}

Estos dos contextos contrastantes de «des-aislamiento» $\mathrm{y}$ «(re) aislamiento» nos enseñaron que, a partir del dominio de metodologías actuales de documentación lingüística, es necesaria una serie de adaptaciones y reinvenciones continuas en y fuera de campo. Esto con el objetivo de obtener resultados mínimamente satisfactorios, de profundizar el conocimiento de esas lenguas, así como de atender las demandas de las comunidades. Frente a esas experiencias, nosotros como lingüistas ganamos nuevas competencias respecto de las metodologías disponibles para la documentación lingüística.

En el caso del guató, la documentación de emergencia consistió en lo siguiente: en un primer momento un intenso trabajo de búsqueda de registros escritos $\mathrm{y}$, sobre todo, grabaciones en audio, que posteriormente vendrían a conectarse a una lengua viva y apenas en los recuerdos de sus dos últimos hablantes. Para hacer aflorar gradualmente esa lengua adormecida de la boca de Vicente y Eufrásia, fue necesaria mucha dedicación, paciencia e insistencia. En campo, los investigadores (Godoy y Balykova) comenzaron las sesiones de elicitación con ítems lexicales referentes a objetos y prácticas cotidianas aún existentes, como cocinar, pescar, cazar, para enseguida lograr aquello que parecía imposible: los primeros textos que contenían desde la descripción de actividades cotidianas hasta narrativas tradicionales.

Ya el trabajo con el pueblo xinane situó a la lingüista en un lugar inesperado entre-lenguas, donde, al dar primacía a la comunicación con los yura, acababa por estorbar el registro y la descripción de la lengua tal como ella es hablada por ellos. Para dar cuenta de este desafío, la metodología de trabajo más apropiada consistió en trazar fronteras explícitas para delimitar las sesiones de elicitación de datos: esos eran los momentos en que los yura ejercían su papel de maestros especialistas, conocedores que se situaban en el lugar de enseñar aquello que es de ellos. Poco a 
poco, la lingüista se fue familiarizando con los préstamos y en su habla cotidiana se volvió más común la siguiente pregunta: «¿Cómo llaman a eso los yura?». Es importante destacar que esa insistencia en separar aquello que es propiamente de su lengua de aquello que es un préstamo, no traduce un deseo purista de frenar o condenar los cambios lingüísticos. Las otras lenguas, en todo caso, son apenas un elemento más que los xinane yura descubren y del cual se apropian en ese momento de emerger de la selva (Gow 2018). Por lo tanto, los préstamos son parte vital de la composición de la fotografía momentánea que es la documentación lingüística dentro de ese proceso de cambios rápidos e intensos. La insistencia de saber y documentar cómo hablan los yura traduce la intención de la lingüista de colocarse en su lugar de aprendiz, transmitiendo a los especialistas un mensaje que los define a ellos como poseedores del conocimiento que ella fue a buscar.

Es importante enfatizar que, en esos dos contextos de documentación lingüística tan contrastantes, el tiempo aparece como un componente central de la metodología de trabajo. Sea el tiempo de examinar archivos en busca de grabaciones antiguas de la lengua guató, o de esperar que los recuerdos emergieran de las bocas de sus últimos hablantes, o de pasar horas y días intentando entender siquiera una frase de la lengua de los yura, o incluso el tiempo de darse cuenta de la práctica de los xinane de prestar palabras y aceptar irrestrictamente el habla incompetente de la lingüista que volvieron intérprete, fue el tiempo que nos permitió centrar la atención, deconstruir expectativas y adaptar metodologías a los desafíos que se presentaron.

Y para dar un paso más allá de las metodologías que aplicamos y reinventamos en nuestras experiencias, aquí también buscamos contribuir para el debate sobre la problematización del concepto de «aislamiento» con una perspectiva que nos parece inédita.

Después de mucha interacción y conversaciones con los yura, hoy sabemos que el llamado «contacto» sucede después de tres generaciones de aislamiento «voluntario». En ese contexto, nos parece errónea la connotación de autodeterminación que la palabra «voluntario» carga. En todo caso, ¿cuán voluntaria puede ser una elección realizada sobre la presión del miedo? No es la primera vez que los yura bajan de tierra alta. Permanecen vivos los relatos de abuelos y bisabuelos que preferían aislarse a continuar sometiéndose a las violencias de los dawa en los cultivos de caucho. Es verdad que el tiempo esfumó la fuerza de esos relatos para las nuevas generaciones. El «contacto» fue pensado, planeado, y cautelosamente ejecutado por jóvenes hombres y mujeres, algunos de ellos parejas: un autodeterminado, acto voluntario de «des-aislamiento». Ellos dicen que los más viejos no tenían coraje. 
Gracias a los dos últimos hablantes de la lengua guató, llegamos a entender los motivos que llevaron al aislamiento de Vicente en la barra del río São Lourenço; la presencia del investigador parece haber desenterrado fragmentos de memorias de una vida que Vicente prefería olvidar. La relación de Gustavo y Kristina con Vicente fue una tentativa, parcialmente frustrada, de «des-aislamiento» mediante la preservación de la lengua. Ya Eufrásia fue «des-aislada» en la periferia de una ciudad, por la persistencia de estos dos mismos investigadores, capturados por la dramática emergencia de documentar una lengua preciosa. Este trabajo continúa para declarar, definitivamente, que el guató existe en el presente. Son historias de (sobre) vidas resilientes de personas y lenguas.

\section{REFERENCIAS}

Almeida, L. M. (2021). Parentes Estrangeiros: intérpretes indígenas no processo de contato com o povo do Xinane (Acre, Brasil) [tesis de doctorado en Antropología]. Universidade Federal do Rio de Janeiro.

Balykova, K. y Godoy, G. (2020). A perda e a retomada do guató. Cadernos de Linguística, l(3). Recuperado de https://cadernos.abralin.org/index.php/cadernos/issue/ view/4 https://doi.org/10.25189/2675-4916.2020.v1.n3.id230

Balykova, K., Godoy, G. y Ferreira, E. (2019). Guató - Mani gotođ zókwẽ maegúhi mani gévú - O guaribão pegou uma mulher. Revista Lingüística, 15(1), 271-302. https://doi.org/10.31513/linguistica.2019.v15n1a25570

Castelnau, F. de (1949). Expedição às regiões centrais da América do Sul. São Paulo: Companhia Editora Nacional.

Chelliah, S. (2001). The role of text collection and elicitation in linguistic fieldwork. En P. Newman y M. Ratliff (eds.), Linguistic Fieldwork (pp. 152-165). Cambridge: Cambridge University Press. https://doi.org/10.1017/CBO9780511810206.008

Eremites, J. O., Milheira, R. G. (2020). Etnoarqueologia de dois aterros Guató no Pantanal: dinâmica construtiva e história de lugares persistentes. Mana, 26(3). https:// doi.org/10.1590/1678-49442020v26n3a208

Fleck, D. W. (2013). Panoan languages and Linguistics. American Museum of Natural History Anthropological Papers, 99. http://dx.doi.org/10.5531/sp.anth.0099

Franchetto, B. y Godoy, G. (2017). Primeiros passos da revitalização da língua Guató: uma etnografia. Revista Lingüistica / Revista del Programa de Pós-Graduação em Lingüistica da Universidade Federal do Rio de Janeiro, 13(1), 281-302. Recuperado de https://revistas.ufrj.br/index.php/rl/article/view/10432 
Franchetto, B., Nonato, R., Camargo Souza, L. (2014). Language Revitalization across the South Pacific. En P. Heinrich y N. Ostler (eds.), Proceedings of the $18^{\circ} \mathrm{FEL}$ Conference (pp. 59-62). Batheaston Villa: Foundation of Endangered Languages.

Gow, P. (2018). «Who Are These Wild Indians»: On the Foreign Policies of Some Voluntarily Isolated Peoples in Amazonia. Tipiti: Journal of the Society for the Anthropology of Lowland South America, 16(1), Artigo 3, 6-20. Recuperado de https://digitalcommons.trinity.edu/tipiti/vol16/iss1/3

Meirelles, J. C. (2018). Terras compartilhadas por povos indígenas isolados e contatados: o Alto Rio Envira como estudo de caso. Tipiti: Journal of the Society for the Anthropology of Lowland South America, 16(1), Artigo 10, 120-124. Recuperado de https://digitalcommons.trinity.edu/tipiti/vol16/iss1/10

Perez Gil, L. (2003). Corporalidade, ética e identidade em dois grupos pano. Ilha Florianópolis, 5(1), 23-45.

Rolando, G. (2018). A Story of Two Videos Plus Coda: Perspectives on «Contact» in Western Amazonia. Tipiti: Journal of the Society for the Anthropology of Lowland South America, 16(1), Artigo 6, 52-68. Recuperado de https://digitalcommons.trinity.edu/tipiti/vol16/iss1/6.

Rondon, F. (1938). Na Rondônia ocidental. São Paulo, Río de Janeiro, Recife, Porto Alegre: Companhia Editora Nacional.

Schmidt, M. (1905). Indianerstudien in Zentralbrasilien. Erlebnisse und ethnologische Ergebnisse einer Reise in den Jahren 1900 bis 1901. Berlín: Dietrich Reimer.

Schmidt, M. (1942a). Resultados da minha expedição bienal a Mato-Grosso: De setembro de 1926 a agosto de 1938. Boletín del Museu Nacional.

Schmidt, M. (1942b). Resultados de mi tercera expedición a los guatos efectuada en el año de 1928. Revista de la Sociedad Científica del Paraguay, 5(6), 41-75.

Schmidt, M. (1951). Anotaciones sobre las plantas de cultivo y los métodos de agricultura de los indígenas sudamericanos. Revista do Museu Paulista (Nova Série), São Paulo, 5, 239-252.

Schmidt, M. (2018). Guató: A língua. Tradução de Kristina Balykova e prefácio de Gustavo Godoy e Kristina Balykova. Cadernos de Etnolinguística. Recuperado de http://www.etnolinguistica.org/mono:5

Siskind, J. (1973). To Hunt in the Morning. Nueva York: Oxford University Press.

Wilson, J. (1959). Guató word list. Summer Institute of Linguistics. 